\title{
The Effect of Compensation, Training and Knowledge Transfer, and Creativity Culture on Employee Performance within the hotel industry in Lebanon
}

\author{
Dana HANKIR* \\ DBA Student, Cyprus International University, Haspolat, Nicosia, North Cyprus \\ Asst. Prof. Dr. Aysen BERBEROGLU \\ Lecturer, Cyprus International University, Haspolat, Nicosia, North Cyprus
}

\begin{abstract}
Within the current stormy economic situation, organizations struggle to survive. They tend to achieve their organizational goals and develop their competencies to meet future demands. Enhancing employees' performance is one way to secure the achievement of organizational goals and development. That been said, all organizations strive to boost the performance of their employees. Noting that, several strategies are applied. Among them, compensation, training and knowledge transfer, and creativity culture tend to increase employees performance. The aim of this study is to assess the effect of these variables on employees' performance. Accordingly, secondary research has been done to come up with dimensions that evaluate the variables of the study. Furthermore, a quantitative approach was done via a questionnaire. Compensation was measured through monetary and nonmonetary compensation; Training and knowledge transfer was measured through training provision, feedback, and self-efficacy; Creativity culture was measured through space of creativity, relationship with supervisor, and job structure. Finally, employees' performance was measured through timeliness, quality, and quantity of work. The questionnaire was randomly distributed over a sample of 400 employees working within the hotel industry in Lebanon. Data was analyzed through SPSS, using correlation, and regression tests. The findings of the study approved the positive correlation between the dependent and independent variables. The results proved that compensation, training and knowledge transfer, and creativity culture positively influence employees' performance. Thus managers should take these variables into account when aiming to boost their employees' performance

Keywords: Compensation, monetary compensation, non-monetary compensation, training and knowledge transfer, training provision, feedback, self-efficacy, creativity culture, space of creativity, relationship with supervisor, job structure, and employee performance
\end{abstract}

DOI: $10.7176 / \mathrm{EJBM} / 12-15-05$

Publication date:May $31^{\text {st }} 2020$

\section{Introduction}

The Performance Management has gained high importance in organizations eager to stay in business in a very turbulent economy which always impose many unpredictable challenges over them. The management of employee performance is an organizational practice that facilitates the alignment of employee metrics, competencies, growth and development and delivery of results. Employee performance is a key component as it influences the overall performance of the organization (Marchington et al., 2016).

Employee performance might be impacted by a myriad of factors comprising of the level of training, the culture and workplace setting, the sort of compensation rendered to the personnel, satisfaction and motivation levels, and also style of management. In accordance to Shen (2004) the management of human resources considers all of the administrative practices and decisions that influence the relationship between an establishment and its staff. The Lebanese hotels sector is the backbone of the tourism industry, and is deemed to be a key contributing component of the overall economy. In fact, statistics indicate that the tourism industry in accountable for more than 35 percent of the economy of the nation (O'Neil, 2016). The way in which these hotels are running is a key aspect of the quality levels of consumer service rendered. Ismail (2013) shed light on the critical role that human resources play in offering outstanding services in the industry. Lebanese hotels, especially the renowned ones, give special care to the management of its human resources, and provide training provisions for staff where they are educated and equipped with the necessary set of skills for guaranteeing consumer satisfaction (O'Neil, 2016). Nonetheless, these performances of employees are largely determined by key factors within the organization.

The aim of the study is to ascertain the various factors that influence employee performance, with an emphasis on the hotel industry in Lebanon. Specifically, the study considers three key aspects including creativity culture, training and knowledge transfer, and compensation.

The hotel sector is a core component of the overall Lebanese tourism industry. In this regard, various entities in the hotel sector in the nation endeavor to come up with numerous and effective ways of increasing the general performance of their personnel. Thereby, the outcomes of this study will render discernments into the different 
factors that impact the performance of personnel and what can be done to enhance such performance. This study is of great value to the various players in the hotel sector.

\section{Literature Review}

\subsection{Theoretical Review}

Armstrong and Baron (1998) defined performance management by "a strategic and integrated approach to delivering success to organizations by improving the performance of the people who work in them and by developing the capabilities of teams and individual contributor." Enhancing employee performance and improving their skills and competencies are critical aspects in the management of performance. Kehoe and Wright (2013) defined employee performance by the ability of the organization to profit from the way its employees are accomplishing their jobs. In the context of achieving performance, employees' satisfaction was highly considered in the management of human resources since the Hawthorne studies that was done in 1924, and it is vital for effective organizations to consider working on enhancing satisfaction, which is interrelated with motivation, and lowering dissatisfaction (French, 2003). Many theories of motivation were developed in order to motivate employees and enhance their performance, among them the Herzberg's motivation-hygiene theory that was established by the psychologist Frederick Herzberg in 1959. It is also called dual-factor or two-factor theory as it is based on possessing two sets of factors in the workplace: Hygiene that are extrinsic to the job, and Motivators that are intrinsic to the job. The presence of hygiene factors reduce dissatisfaction and demotivation of employees, whereas the presence of motivators increase their satisfaction and motivation; and hence better performance could be achieved. Reference to Herzberg (1987) it is critical for successful organizations to remove dissatisfaction by enhancing both the hygiene factors (policies, supervision, pays and fringe benefits, interpersonal relations, and working conditions), and the motivators ones (accomplishment, appreciation, the job itself, responsibility, development and growth, and participation in taking decisions). Organizations should work on job enrichment to enhance satisfaction, and this would impose the necessity of possessing advanced competencies and taking more responsibility and wide control over how fulfill jobs (Herzberg, 2009). Therefore, successful organizations should conduct a set of practices and implement many systems aiming to eliminating dissatisfaction and nurturing satisfaction, and hence increasing performance. Setting and improving policies, promoting effective supervision that is supportive and constructive, enhancing equity, providing good payments and fringe benefits, and building significant jobs and healthy workplace become key to remove dissatisfaction. Whereas, opening opportunities for the employees for achievements and progress, giving them additional responsibilities in their jobs and independence in taking decisions, promoting them and recognizing their contributions, and providing them with efficacious training become key to enhance their satisfaction.

\subsection{Empirical Review}

\subsubsection{Compensation and its effect on employee performance}

Compensation is all the rewards received by employees as a result to their work in the organization (Ardana, 2012). It comprises both financial and non-financial rewards. It is composed of cash rewards like salaries/wages, bonuses, accommodation loan and other non-cash rewards like recognition, promotion, and fringe benefits. Compensation is a significant section in managing human resources and make them satisfied and motivated in their jobs (Armstrong and Brown, 2005). The position that an employee hold and the contribution that an employee do in fulfilling his tasks and duties affect the amount of payments he receives in many organizations (Armstrong and Taylor, 2014). Salaries/ wages and bonuses are critical motivators used to enhance employee performance (Agwu, 2012 ; 2013). Cash is important for employees but it is not the only factor motivating employees to perform better, non-monetary incentives are another important factor that should be considered (Ngatia, 2017). Both adequate monetary and non-monetary compensation motivate employees and enhance their performance (Nkansah, 2017). Non-monetary compensation like the opportunity to advance in the career is also vital for better employee satisfaction and performance, besides both decent training and payments (Syukra, 2014). Intrinsic rewards like recognition and promotion encourage employees to enhance their output (Shahzadi et al., 2014). Literature has shown that compensation is very vital for employees, and possess a positive effect on their performance. Darma and Supriyanto (2017) shown how compensation in its both forms positively affects performance, with the satisfaction considered as a median variable. Other authors also found positive relationship between compensation and employee performance (Milkovich and Newman, 2001; Hameed et al., 2014; Yousaf et al., 2014; Zameer et al., 2014).

2.2.2 Training and Knowledge Transfer and its effect on employee performance

Training is a set of processes conducted in order to teach employees new set of skills and competencies so they be able to achieve efficiently and effectively their targets, be ready to face any potential challenges, and meet future demands. Training and performance are two components that are always present in any successful performance management approach, as training is always conducted to build capacities needed to fulfill the targeted performance and exceeding it. It is a dynamic and vital component of a successful management of human resources 
(Noe and Peacock, 2008). An enhancement in the performance of employees takes place when these individuals are provided with effective training (Bratton and Gold, 2017). Many authors found a positive impact of the presence of effective training systems on employee performance (Harrison, 2000; Farooq and Khan, 2011; Najeeb, 2013; Dobre and Ovidiu-Iliuta, 2013). In the context of possessing effective training systems able to effectively and successfully enhance performance, Velada and Caetano (2007) and Velada et al. (2007) discussed how transference of knowledge declines over time. This imposes the necessity of possessing training systems that are able to transfer knowledge to the workplace so that employees are able to use what is acquired and learned when they are fulfilling their daily tasks and duties. Many researchers considered the importance of transference of knowledge (Holton et al., 2000; Argote and Ingram, 2000; Holton and Baldwin, 2003; Gegenfurtner et al., 2013). In the research conducted by Diamantidis and Chatzoglou (2014), they evaluated the output of the training sessions that possess the ability to transfer knowledge to the workplace. They found out a positive correlation. Training systems having this capacity are systems that, according to previous literature, possess an effective design able to transfer the content of the training to the workplace, self-efficacious trainees whose personal characteristics will impact the degree of transference to the workplace, and an environment that provide feedback to the employees reflecting a climate of support and encouragement to implement the freshly acquired content.

2.2.3 Creativity Culture and its effect on employee performance

The culture of the organization is an important factor that should be considered when managing performance. It is critical to carefully inspect the culture when conducting changes in the development system (Stiles and Kulvisaechana, 2003). Vijaye Sathe (1985) defined Culture by "The set of important understandings (often unstated) that members of a community share in common". Handy (1986) described it by a shared set of standards, values, and beliefs. The performance of employees is affected positively by the degree to which these individuals feel satisfied and at ease with the workplace environment (Denison and Mishra 1995). The more the employees feel positive with the culture the more they will be motivated to exert effort and achieve better results. Wanjiku (2014) discussed how the culture of the organization may affect performance either positively or negatively, as it affects the shared philosophy, how processes and tasks are undertaken, in addition to other aspects. Ample research found a positive relationship between strong culture and employee performance (Calori and Sarnin, 1991; Gordon and Christensen, 1993; Awadh and Saad, 2013). Encouraging creativity in the workplace strengthens interpersonal relations among individuals and triggers employees to generate new ideas, and find creative and new ways to accomplish their goals and solve problems. Scott and Bruce (1994) studied the determinants of creative behavior in the workplace. Creativity is explained by "the production of novel, useful ideas or problem solutions. It refers to both the process of idea generation or problem solving and the actual idea or solution" (Amabile 2005, p. 368). Ample literature studied the effect of creativity on the output of employees. Some stated the presence of a positive relationship, while others stated a negative one. Kalmi and Kauhanen (2008) considered this contradiction and found that fostering a workplace of innovation has positive impact on employees' output. Bratnicka and Bratnicki (2013) discussed novelty and usefulness as two dimensions to be considered in a culture of creativity aiming to increase the performance of its staff. Other literature also discussed how creativity affects the performance of employees and the organization (Pitta, 2008; Syed and LIN, 2013; Bratnicka and Bratnicki, 2013). Hassan et al (2013) studied how the creativity of the employee can affect his performance. Creative employees lead to creative results and better performance. Both job-complexity and effective relationship between employee and supervisor had direct effect in enhancing the performance of employees; noting that job complexity reflects the characteristics of job that is enriched; it was an expansion of the recommendation of Herzberg to enrich jobs (Hackman and Oldham, 1980). In the research conducted by De stobbeleir et al. (2011), they shed light on the importance of providing employees with space in their work, encouraging them to be creative, and making creativity as a work setting triggering employees to ask for feedback due to its importance in creative behaviors.

2.2.4 Employee Performance

Performance was defined by Kumari \& Malhotra (2012, p.78) with "What is expected to be delivered by an individual or a set of individuals within a timeframe. What is expected to be delivered could be stated in terms of results or efforts, tasks and quality, with specification of conditions under which it is to be delivered". Dobre and Ovidiu-Iliuta (2013) shed light on the importance of motivating individuals by empowerment and recognition in the process of enhancing performance; in that context, managers should work on eliminating dissatisfaction and enhancing motivators. It is vital to possess effective training and learning, suitable compensation, and a climate of motivation in the workplace. Performance of employees is positively correlated by the practices adopted in human resources management comprising compensation and incentives, and training and development (Jouda et al., 2016). Moreover, researchers discussed and shown how performance is affected by the presence of a strong culture (Gordon \& DiTomaso, 1992; Denison and Mishra, 1995; Wambugu, 2014), and others put emphasis on the importance of creativity of employees and the presence of a culture that encourage creativity in enhancing employee performance (De Stobbeleir, 2011; Hassan et al, 2013; Bratnicka and Bratnicki, 2013). Performance of employees was considered in the majority of studies interested in assessing organizational performance. The performance of employees is regarded as a snapshot of the performance of organizations, as they are both 
correlated with each other (Nassazi, 2013). Through literature, employee performance was measured through different dimensions like satisfaction, commitment, quality, quantity, timeliness, efficiency, and effectiveness.

\section{Materials and Methods}

This study aimed to assess relationships between dependent and independent variables. Therefore, quantitative approach was designed via a questionnaire. This approach was deemed ideal because it rendered both statistical and arithmetic metrics to delineate the relationship that is existent between employee performance in the Lebanese hotel sector and the three key variables including compensation, training and knowledge transfer, and creativity culture within the organizations. Based on secondary research that tested the mentioned above variables, some dimensions were adopted. Shahzadi et al. (2014), Zameer et al. (2014), Hameed at al. (2014), and Nkansah (2017) discussed compensation. They measured it through 2 main factors; monetary and non-monetary. These two dimensions were hence adopted in this research for the compensation variable. At the same time, Farooq and Khan (2011) assessed the effect of both training and feedback on performance, and Diamantidis and Chatzoglou (2014) measured the training results and it effect on employee performance with emphasis on the transfer of knowledge; thus training provision, self-efficacy, and finally feedback were adopted from them in this research as dimensions for training and knowledge transfer. Similarly, Hassan et al. (2013) and De Stobbeleir (2011) studied the impact of employee creativity on employees' performance and the role that the feedback-seeking behavior play in creative performance; accordingly space of creativity, relationship with supervisor and job structure were adopted for creativity culture variable. At the end, timeliness, quality of work, and quantity of work were adopted as dimensions for employee performance from the study of Thaief et al. (2015) where they assessed the effect of compensation, training, and work discipline on employee performance.

After identifying the variables and their dimensions from the literature review, statements related to each dimension were accordingly replicated, and the questionnaire was constructed. A copy of the questionnaire was then distributed to leaders in the industry for their careful inspection and comments. Additionally, and after considering their comments, a pilot test was done over a group of 10 employees to check the clarity and workability of the tool. Consequently, in order to ensure the ability of the questionnaire to fulfill its objectives, all the comments were considered and necessary changes were done on the questionnaire.

The questionnaire was later randomly distributed to 400 employees working within the hotel industry in Lebanon on the basis of convenience. The sample size was calculated by using Cochran's formula. The data was collected via an online survey, phone calls, and in person. The responses of these employees were later entered into SPSS for testing the reliability and validity of the questionnaire, then to conduct analysis.

Reliability test was the first test done on each group of statements constituting a dimension in the questionnaire. All values of Cronbach's alpha scored between 0.748 and 0.934 (average 0.866), hence all dimensions were reliable. After approving this, Factor analysis was the second test done. The aim of this test was to check the validity of the structured questionnaire and to reduce groups of statements into one item. In this test, Principal Component Analysis technique and Varimax Rotation with Kaiser Normalization method were adopted. Statements having a loading less than $40 \%$ were excluded. The significance of all KMO and Bartlett's Test scored 0.000 smaller than 0.05 indicating that the matrix correlation is not an identity matrix. Factor loadings scored between 0.7 and 0.9 indicating that the extracted items highly explains their corresponding variables. Moreover, the variance contribution rate were also high between 63 and $90 \%$ reflecting that these extracted items are scientifically adequate for being used in further analysis.

Accordingly, each group of statements related to each dimension under independent variables were grouped into one item, and all the statements of employee performance comprising all its related dimensions, were all together reduced into one item. Eventually, nine items resulted, representing the eight dimensions of the measured independent variables in addition to the dependent variable. No non-fitting statements were found for the dimensions of the independent variables, while two statements were removed from the ones related to employee performance on the basis of possessing high correlations of 0.845 and 0.789 (the determinant of its correlation matrix was less than 0.00001). Descriptive statistics were done to compute the distribution of responses regarding respondents' demographics and nature of work. Finally, Pearson correlation and regression were the last tests done to assess the relationships among variables and test the effect of independent ones on dependent.

\section{Variables and Dimensions}

The three independent variables are as follow with their adopted dimensions:

- Compensation

* Monetary: financial incentives comprising salaries/wages, gain sharing, and accommodation.

* Non-monetary: non-financial incentives comprising promotion, recognition, and fringe benefits.

- Training and Knowledge Transfer

* Training provision: Set of processes designed and adopted in a way opening opportunities for the employees to learn new skills and knowledge that are effective and beneficial. 
* Feedback: employees are getting a supportive and constructive feedback from their supervisors to get motivated in initiating ideas and to enhance their output.

* Self efficacy: The employees have the personal capacities to easily capture knowledge on their own from the provided training and the workplace environment and use it freely in their jobs.

- Creativity Culture

* Job structure: The jobs are comprising the five features of enriched jobs ("variety, identity, significance, autonomy, and feedback")

* Relationship with supervisor: employees have good relationship with their supervisors. Their supervisors are considering their needs and supporting them.

* Space of creativity: The organization is providing employees with the freedom of being creative and giving new ideas and solutions.

The dependent variable is employee performance with the following dimensions:

- Quality: the quality of the job done meet the adopted standards and satisfying to supervisors and clients.

- Quantity: the quantity of job tasks accomplished within a timeframe is good enough and satisfying.

- Timeliness: employees are able to complete their job efficiently and within the adequate timeline.

\section{Hypothesis}

H1: Compensation of the employees has positive influence on employee performance. H1a: Monetary compensation has positive influence on employee performance.

H1b: Non-monetary compensation has positive influence on employee performance.

H2: Training and knowledge transfer has positive influence on employee performance $\mathrm{H} 2 \mathrm{a}$ : Training provision has positive influence on employee performance.

$\mathrm{H} 2 \mathrm{~b}$ : Feedback has positive influence on employee performance

H2c: Self-efficacy has positive influence on employee performance.

H3: Creativity culture of the organization has positive influence on employee performance H3a: Job structure has positive influence on employee performance

H3b: Relationship with supervisor has positive influence on employee performance.

$\mathrm{H} 3 \mathrm{c}$ : Space of creativity has positive influence on employee performance.

H4: Compensation, training and knowledge transfer, and creativity culture jointly have positive influence on employee performance.

\section{Analysis and findings}

The aim of the study was to assess the influence of compensation, training and knowledge transfer, and creativity culture on employees' performance. The study adopted Pearson correlation to check if a relationship exist among the variables, and then simple and multiple linear regression to check the effect of the independent variables on the dependent one (Results are shown in tables 1,2, and 3 attached).

All dimensions related to the study independent variables proved to have positive correlation with employee performance as they all scored significance less than 0.05 and all have positive values of correlation. Job structure showed the highest correlation $78.9 \%$, then space of creativity $67.7 \%$, then self-efficacy $63.4 \%$, then relationship with supervisor $58.6 \%$, then training provision $53.4 \%$, then feedback $53.3 \%$, then non-monetary compensation $43.4 \%$, and then lastly monetary compensation that scored $26.8 \%$.

Regression analysis was done in three scenarios to check the effect of the independent variables on employees' performance. Each scenario took different independent variables. First scenario, each of the dimensions of the independent variables were considered each one apart. It was found that each of all the dimensions related to independent variables has positive influence on employee performance. The highest influence was for job structure $62.3 \%$, then space of creativity $45.8 \%$, then self-efficacy $40.2 \%$, then relationship with supervisor $34.3 \%$, then training provision $28.5 \%$, then feedback $28.4 \%$, then non-monetary compensation $18.8 \%$, then non-monetary compensation $7.2 \%$ (look at table 1); Second scenario, each of the independent variables were considered each one apart. Each of the independent variables comprising its related dimensions was moderately to strongly positively correlated with employee performance and has positive influence over it. Creativity culture has the highest correlation $44.2 \%$ and highest influence $63.8 \%$, then training and knowledge transfer has moderate correlation $64.3 \%$ and moderate influence $41.3 \%$, and lastly compensation has the lowest correlation $44.2 \%$ and lowest influence of only $19.5 \%$ (look at table 2). Moreover, it is importance to note that all VIF scored less than five indicating no multicollinearity; Third scenario, all the independent variables were considered all together. All of the independent variables together are strongly positively correlated with employee performance $79.9 \%$ and has good positive influence over it $65.2 \%$ (look at table 3 ). All VIF scored less than five indicating no multicollinearity.

\section{Discussion and conclusions}

The findings of the paper proved the significant positive influence of compensation, training and knowledge 
transfer, and creativity culture on employee performance. These results are in agreement with previous scholarly findings indicating a positive correlation of employee performance with compensation (Zameer et al., 2014; Hameed at al., 2014; Nzyoka \& Orwa, 2016; Nkansah, 2017). Shahzadi et al. (2014) has found a positive correlation between employee performance and intrinsic rewards like recognition and promotion. Furthermore, Nyaribo et al. (2016) proved the positive effect of non-monetary compensation on employee performance, where many aspects were included like the environment and the training.

The findings are also in agreement with previous findings indicating a positive correlation of employee performance with training and knowledge transfer (Velada and Cetano, 2007; Velada et al., 2007; Khan and Farooq, 2011; Diamantidis and Chatzoglou, 2014). Velada and Caetano (2007) considered the importance of training provision in the context, as practical implications put emphasis on training design and content to suit effectively the employees' needs. Farooq and Khan (2011) showed how training and feedback affects performance. Whereas Velada et al. (2007) and Diamantidis and Chatzoglou (2014) showed the importance of the three adopted dimensions in the context of possessing a training system able to transfer knowledge and hence increasing the performance of employees.

Moreover, the results are in agreement with previous scholarly findings indicating a positive correlation between employee performance and creativity culture (De Stobbeleir et al., 2011; Hassan et al., 2013; Syed and Lin, 2013). In the research of Hassan et al. (2013) it was proved how both job structure and relationship with supervisor positively affect performance. Whereas, De Stobbeleir et al. (2011) assessed how the perceived support for creativity enhances the request and monitoring of feedback from the environment leading to high performance, putting emphasis on how the space of creativity affects performance.

Consequently, it is imperative for managers to comprehend that a pay rise only is not sufficient to enhance the performance of the personnel, it is necessary to develop non-financial compensation deals. Moreover, it is vital to implement training systems able to transfer knowledge where trainees positively perceive the provision of such training design, and openly get constructive feedback. At the same time, employees should have the initiative to learn. Additionally, managers should provide personnel with autonomy of being creative through time and space in a supportive environment that considers their needs. Moreover, the adoption of enriched jobs would be helpful in fostering a culture of creativity and hence enhancing performance.

\section{Limitations and future research}

Some limitations were faced by the author like industry where the study was conducted only in hotels and its results could not be generalized on other industries or sectors, economic stagnation where the responses of employees could be biased following their psychological state that is affected by the country situation, subjective assessment of employee performance as it was measured as a perception from the side of employees, and exploratory variables were limited to three at the time that employee performance is known to be affected by broader set of variables. Therefore, it is recommended that future research considers these issues and adopt different industries or sectors like schools or hospitals, adopt different independent variables like mentoring due to its effect in streamlining efforts, adopt different sets of dimensions like considering the competency of the trainer in the training context, and to try to get tangible data regarding the real performance of employees.

\section{References}

Agwu, M. (2012). Impact of Employees Safety Culture on Organisational Performance in Shell Bonny Terminal Integrated Project (BTIP). European Journal of Business and Social Sciences, 1 (5), 70-82.

Agwu, M. (2013). Impact of Fair Reward System on Employees Job Performance in Nigerian Agip Oil Company Limited Port-Harcourt. British Journal of Education, Society \& Behavioural Science 3(1), 47-64.

Amabile, T. M., Barsade, S. G., Mueller, J. S., and Staw, B. M. (2005). Affect and Creativity at Work. Administrative Science Quarterly, 50(3), 367-403.

Ardana, I. K. dkk. (2012). Manajemen Sumber Daya Manusia. Edisi Pertama. Yogyakarta: Graha Ilmu.

Argote, L., \& Ingram, P. (2000). Knowledge transfer: A basis for competitive advantage in firms. Organizational behavior and human decision processes, 82(1), 150-169.

Armstrong, M., \& Brown, D. (2005). Reward Strategies and Trends in the United Kingdom: The Land of Diverse and Pragmatic Dreams. Compensation \& Benefits Review, 37(4), 41-53.

Armstrong, M. and Baron, A., (1998). Performance Management, London: IPD.

Armstrong, M. and Taylor, S., (2014). Armstrong's handbook of human resource management practice. Kogan Page Publishers.

Awadh, A. M., and Saad, M. Y. (2013). Impact of Organizational Culture on Employee Performance. International Review of Management and Business Research, 2(1), 168

Bratnicka, K., and Bratnicki, M. (2013). Linking Two Dimensions of Organizational Creativity to Firm Performance: The Mediating Role of Corporate Entrepreneurship and the Moderating Role of Environment. Advances in Business-Related Scientific Research Journal, 4(2), 153-163. 
Bratton, J. and Gold, J., (2017). Human resource management: theory and practice. Red Globe Press.

Calori, R., \& Sarnin, P. (1991). Corporate culture and economic performance: A French study. Organization studies, 12(1), 049-74.

Darma, P. S., \& Supriyanto, A. S. (2017). The effect of compensation on satisfaction and employee performance. Management and Economics Journal, 1(1), 69-77.

De Stobbeleir, K. E., Ashford, S. J., \& Buyens, D. (2011). Self-regulation of creativity at work: The role of feedback-seeking behavior in creative performance. Academy of management journal, 54(4), 811-831.

Denison, D. R., and Mishra, A. K. (1995). Toward a theory of organizational culture and effectiveness. Organization Science, 6(2), 204-223.

Diamantidis, A. D., \& Chatzoglou, P. D. (2014). Employee post-training behaviour and performance: evaluating the results of the training process. International Journal of Training and development, 18(3), 149-170.

Dobre, and Ovidiu-Iliuta. (2013). Employee motivation and organizational performance. Review of Applied Socio-Economic research, 5(1), 53-60.

Farooq, M., \& Khan, M. A. (2011). Impact of training and feedback on employee performance. Far east journal of psychology and business, 5(1), 23-33.

French, W. L. (2003). Human resources management. Houghton Mifflin College Division.

Gegenfurtner, A., Veermans, K. and Vauras, M. (2013). Effects of computer support, collaboration, and time lag on performance self-efficacy and transfer of training: a longitudinal meta-analysis. Educational Research Review, 8, 75-89.

Gordon, G. G., \& Christensen, E. (1993). Industry influences on the relationships between management culture and performance. In national meeting of the Academy of Management, Atlanta, GA.

Gordon, G. G., \& DiTomaso, N. (1992). Predicting corporate performance from organizational culture. Journal of management studies, 29(6), 783-798.

Hackman, J. R., \& Oldham, G. R. (1980). Work redesign. Reading, MA: Addison Wesley.

Hameed, A., Ramzan, M., and Zubair, H. M. K. (2014). Impact of compensation on employee performance (empirical evidence from banking sector of Pakistan). International Journal of Business and Social Science, 5(2).

Handy C. B. (1986): Understanding Organizations, 3rd ed. Penguin Books, Harmondswo

Harrison, R. (2000). Employee Development. Silver Lakes, Pretoria. Beekman Publishing

Hassan, M. U., Malik, A. A., Hasnain, A., Faiz, M. F., \& Abbas, J. (2013). Measuring employee creativity and its impact on organization innovation capability and performance in the banking sector of Pakistan. World Applied Sciences Journal, 24(7), 949-959.

Herzberg, F., Mausner, B., \& Snyderman, B. B. (1959). The Motivation to Work, John Wiley \& Sons. Inc., New York, 195.

Herzberg, F.I. (1987), “One more time: How do you motivate employees?”, Harvard Business Review, Sep/Oct. $87,65(5), 109-120$.

Herzberg, F. (2009). One more time: How do you motivate employees? Cambridge, MA: Harvard Business School Press.

Holton III, E. F., Bates, R. A., \& Ruona, W. E. (2000). Development of a generalized learning transfer system inventory. Human resource development quarterly, 11(4), 333-360.

Holton III, E. F., Baldwin, T. T., \& Naquin, S. S. (2000). Managing and changing learning transfer systems. Advances in developing human resources, 8, 23-35.

Holton III, E. F., \& Baldwin, T. T. (2003). Improving learning transfer in organizations. John Wiley \& Sons.

Ismail, H. (2013). Exploring employee involvement in hotels in Lebanon: a case study. Journal of Management Policy and Practice, 14(2), 62-75.

Jouda, A. A., Ahmad, U. N., \& Dahleez, K. A. (2016). The Impact of HRM Practices on Employees Performance: The Case of Islamic University of Gaza (IUG) in Palestine. International Review of Management and Marketing, 6(4), 1080-1088.

Kalmi, P., and Kauhanen, A. (2008). Workplace Innovations and Employee Outcomes: Evidence from Finland. Industrial Relations. Industrial Relations: a journal of economy and society, 47(3), 430-459.

Kehoe, R.R. and Wright, P.M., (2013). The impact of high-performance human resource practices on employees' attitudes and behaviors. Journal of management, 39(2), 366-391.

Kumari, N., and Malhotra, R. (2012). Effective Performance Management System for Enhancing Growth. Global Management Journal, 4 (1/2), 77-85

Marchington, M., Wilkinson, A., Donnelly, R. and Kynighou, A., 2016. Human resource management at work. Kogan Page Publishers.

Milkovich, G. F, and Newman, J.M. (2001). Compensation Approach. Boston: Irwin, 508p.

Najeeb, A. Z. (2013). The impact of training and information and communication technology on employee's performance: an empirical study on pharmaceutical manufacturing companies in Amman (doctoral 
dissertation, Middle East University).

Nassazi, A. (2013). Effects of training on employee performance: Evidence from Uganda. A Thesis Submitted to University of Applied Sciences, Business Economics and Tourism Department, Uganda, 1-59

Ngatia, Z. M. (2017). The Influence of Non-Monetary Rewards on Employee Performance in Muranga Water and Sanitation Company, Murang'a County. Doctoral dissertation.

Nkansah, E. (2017). The impact of monetary and non-monetary incentives on employee's motivation: a case of non-teaching staff of Kumasi Polytechnic (Doctoral dissertation).

Noe, R. A., \& Peacock, M. (2008). Employee training and development. New York: McGrawHill, Inc.

Nyaribo, O. L., (2016). The Effect of Non-Financial Compensation on Employee Performance of Micro-Finance Institutions: A Case of Wakenya Pamoja Sacco, Kisii County, Kenya. Imperial Journal of Interdisciplinary Research, 2(6), 103-126

Nzyoka, C. M., \& Orwa, B. H. (2016). The relationship between Total compensation and employee performance in the insurance industry, case of Mayfair insurance company limited. Psychology and Behavioral Sciences, $5(1), 20$.

O'Neill, Z. (2016). All strangers are kin: adventures in Arabic and the Arab world. Boston: Houghton Mifflin Harcourt.

Pitta, D. A., Wood, V. R., \& Franzak, F. J. (2008). Nurturing an effective creative culture within a marketing organization. Journal of Consumer Marketing, 25(3), 137-148

Sathe, V. (1985). Culture and related corporate realities: Text, cases, and readings on organizational entry, establishment, and change. Richard D Irwin.

Scott, S. G., \& Bruce, R. A. (1994). Determinants of Innovative Behavior: A Path Model of Individual Innovation in the Workplace. Academy Of Management Journal, 37(3), 580-607.

Shahzadi, I., Javed, A., Pirzada, S. S., Nasreen, S., \& Khanam, F. (2014). Impact of employee motivation on employee performance. European Journal of Business and Management, 6(23), 159-166.

Shen, M. (2004), Well-being in the workplace and its relationship to business outcomes, A Review of the Gallup Studies, Flourishing, The Positive Person and the Good Life, Chapter 9. In Keyes, C. L. M., \& Haidt, J. 205224.

Stiles, P., \& Kulvisaechana, S. (2003). Human capital and performance: A literature review. DTI.

Syed, N., \& Xiaoyan, L. I. N. (2013, March). Relationship between human resource management practices and enterprise innovation: Mediating role of creative culture. In Proceedings of the 2013 International Conference on Information, Business and Education Technology (ICIBET 2013). Atlantis Press.

Syukra, A., (2014). The Relationship between Training, Compensation and Employment Promotion with Labor Productivity Employees in Public Health Centre (Puskesmas) of Bukittinggi-West Sumatera, Indonesia. Global Journal of Biology, Agriculture and Health Sciences 3(2).44-48

Thaief, I., \& Baharuddin, A. (2015). Effect of training, compensation and work discipline against employee job performance. Rev. Eur. Stud., 7, 23.

Velada, R. and Caetano, A. (2007). Training transfer: the mediating role of perception of learning. Journal of European Industrial Training, 31(4), 283-296.

Velada, R., Caetano, A., Michel, J. W., Lyons, B. D., \& Kavanagh, M. J. (2007). The effects of training design, individual characteristics and work environment on transfer of training. International Journal of Training and Development, 11(4), 282-294.

Wambugu, L. W. (2014). Effects of Organizational Culture on Employee Performance (Case Study of WartsilaKipevu Ii Power Plant). European Journal of Business and Management, 6(32), 80-91

Wanjiku, N. A. (2014). Effect of Organization Culture on Employee Performance in Non Governmental Organizations. International Journal of Scientific and Research Publications, 4(11).

Yousaf, S., Latif, M., Aslam, S., \& Saddiqui, A. (2014). Impact of financial and non financial rewards on employee motivation. Middle-East journal of scientific research, 21(10), 1776-86.

Zameer, H., Ali, S., Nisar, W., \& Amir, M. (2014). The impact of the motivation on the employee's performance in beverage industry of Pakistan. International journal of academic research in accounting, finance and management sciences, 4(1), 293-298. 
Figure 1: Conceptual Model showing variables and corresponding dimensions

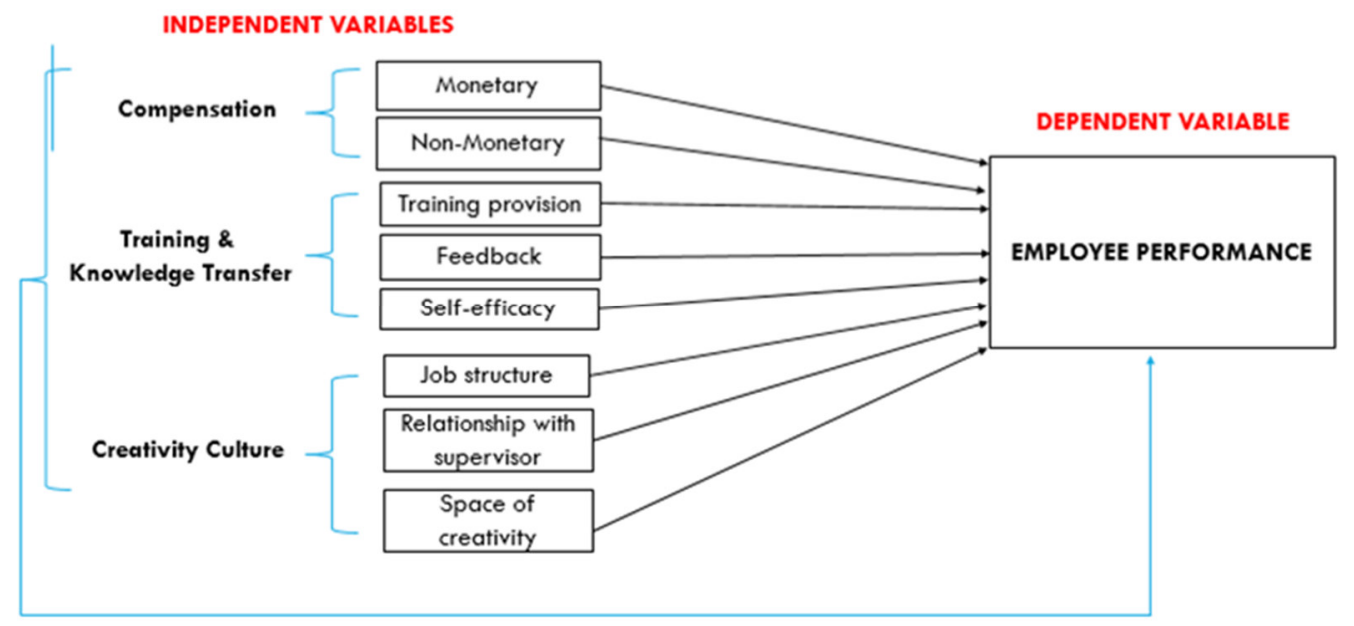

Table 1. Results of correlation and regression among each of the dimensions and employee performance (EP)

\begin{tabular}{|c|c|c|c|c|c|c|}
\hline \multirow[b]{2}{*}{$\begin{array}{l}\text { Dimensions of independent } \\
\text { variables }\end{array}$} & \multicolumn{2}{|c|}{ Correlation results } & \multicolumn{4}{|c|}{ Regression Model summary } \\
\hline & $\begin{array}{l}\text { Pearson } \\
\text { Correlation }\end{array}$ & $\begin{array}{l}\text { Sig. } \\
\text { tailed })\end{array}$ & $\mathrm{R}$ & $\begin{array}{l}\mathrm{R} \\
\text { Square }\end{array}$ & $\begin{array}{l}\text { Adjusted } \\
\text { R Square }\end{array}$ & $\begin{array}{l}\text { Std. error of } \\
\text { estimate }\end{array}$ \\
\hline Monetary Compensation (M) & $.268 * *$ & 0.000 & $.268^{\mathrm{a}}$ & .072 & .069 & .96956284 \\
\hline Non-monetary Comp. (NM) & $.434 * *$ & 0 & $.434^{\mathrm{a}}$ & .188 & .186 & .91201994 \\
\hline Training Provision (TP) & $.534 * *$ & 0.000 & $.534^{\mathrm{a}}$ & .285 & .283 & .85143141 \\
\hline Feedback $(\mathrm{F})$ & $.533 * *$ & 0 & $.533^{\mathrm{a}}$ & .284 & .282 & .84776195 \\
\hline Self-efficacy (SE) & $.634 * *$ & 0 & $.634^{\mathrm{a}}$ & .402 & .401 & .77401171 \\
\hline Job Structure (JS) & $.789 * *$ & 0.000 & $.789^{\mathrm{a}}$ & .623 & .622 & .62158035 \\
\hline Relationship with sup. (RS) & $.586 * *$ & 0 & $.586^{\mathrm{a}}$ & .343 & .341 & .81159385 \\
\hline Space of creativity (SC) & $.677 * *$ & 0 & $.677^{\mathrm{a}}$ & .458 & .456 & .73738065 \\
\hline
\end{tabular}

Table 2. Results of multiple linear regression among each of independent variables and employee performance

\begin{tabular}{|l|r|r|r|r|}
\hline $\begin{array}{l}\text { Each of Independent Variables } \\
\text { comprising its dimensions }\end{array}$ & \multicolumn{2}{|c|}{ Regression Models Summary } \\
\cline { 3 - 5 } EP & $\mathrm{R}$ & R Square & Adjusted R Square & $\begin{array}{l}\text { Std. } \\
\text { estimate }\end{array}$ \\
\hline Compensation (M \& NM) & $.442^{\mathrm{a}}$ & .195 & .191 & .91428005 \\
\hline $\begin{array}{l}\text { Training \& Knowledge } \\
\text { Transfer (TP \& F \& SE) }\end{array}$ & $.643^{\mathrm{a}}$ & .413 & .409 & .77390277 \\
\hline $\begin{array}{l}\text { Creativity Culture (JS \& RS \& } \\
\text { SC) }\end{array}$ & $.799^{\mathrm{a}}$ & .638 & .635 & .61084036 \\
\hline
\end{tabular}

Table 3. Results of multiple linear regression among all the independent variables comprising all dimensions together and employee performance

\begin{tabular}{|l|r|r|r|r|}
\hline \multirow{2}{*}{$\begin{array}{l}\text { All of Independent Variables } \\
\text { comprising its dimensions }\end{array}$} & \multicolumn{4}{|l|}{ Regression Model Summary } \\
\cline { 2 - 6 } \begin{tabular}{l}
$\rightarrow \mathrm{EP}$ \\
\cline { 3 - 6 }
\end{tabular} & $\mathrm{R}$ & \multicolumn{1}{|l|}{ R Square } & Adjusted R Square & $\begin{array}{l}\text { Std. } \\
\text { estimate }\end{array}$ \\
\cline { 2 - 6 } & $.808^{\mathrm{a}}$ & .652 & .644 & .61758763 \\
\hline
\end{tabular}

